\title{
Residential Telephone Service and Prices in New Zealand Since Deregulation
}

\author{
Lewis Evans
}

A CCESS by all households to utility networks has traditionally been a paramount goal of public policy. In telecommunications, such universal service is held to embody the goal of 'a telephone in every dwelling' and to maximise the benefit of the network to all subscribers.

Since the 1970s, a worldwide wave of change in the management of utilities has led to less regulation and more private ownership. Countries have mounted the wave at different points. The deregulation of New Zealand telecommunications occurred in 1989; but it was preceded by scarcely less important policy changes in 1986 , and it took place in the context of economy-wide liberalisation. Now it is providing evidence about the performance of deregulated utilities.

The key finding is that, despite a significant increase in the real price of access, the residential telephone penetration rate of all households has not declined. Given the extensive fall in the real price of usage charges, households appear to choose access on the basis of the price of the bundle of services that access provides rather than the price of access alone. The real price of this bundle has declined over the period of the present study.

Regulation has traditionally held down residential, particularly local, rates by cross-subsidising them from business and long-distance rates. However, crosssubsidisation is very hard, even impossible in the long run, to maintain where freedom of entry exists to all facets of the business, as it does in New Zealand. It appears that the price of a residential bundle has fallen to a point that sustains access itself - which suggests that regulations that inhibit competition in order to crosssubsidise access are unnecessary for the attainment of universal service. This conclusion is identical to that reached by Hausman, Tardiff and Belinfante (1993), who analyse the price rebalancing that took place in the US on the break-up of AT\&T.

\section{The Policy Background}

The details of New Zealand's deregulation of telecommunications are sketched in Boles de Boer and Evans (1996). Key features include the absence of an industryspecific regulator and the government's retention of one share in Telecom New Zealand, which was privatised in 1990 . Broadly, the terms of this 'Kiwi Share' require the company to retain a residential local-call option with no usage charge, to 
limit monthly access rental charges to rural customers to the levels that apply to urban customers, and to limit any price increase in the access rental charge of residential customers to the rate of increase in the Consumers' Price Index (CPI). Any tariff rebalancing after the sale would have to maintain, in real terms, the single-line residential rental at or below its level in late 1990. Prior to privatisation, however, Telecom as a state-owned enterprise had raised its residential-line rental substantially.

Data are available for the period 1986-95. Any analysis of the residential telephone subscribership over this period should take into account all changing factors that are likely to affect it. In addition to tariff rebalancing, changes in the state of the economy and in telephony-targeted benefits are likely to have been important.

Demand for access will be affected by income and technical change as well as price. During the late 1980s and early 1990s, New Zealand experienced a deep recession. As Figure 1 shows, between March 1987 and March 1993 real income per head did not grow at all and the unemployment rate increased from 4.1 per cent to 10.2 per cent. Towards the end of the period, the recession ended, real income per head of population grew in 1994 and 1995, and the unemployment rate fell from 9 per cent to 5.9 per cent between September 1993 and September 1995. These changes were the consequence of economy-wide restructuring and the status of the business cycle. They affect the interpretation of the effect of price changes on household decisions of that period, particularly those of low-income households.

\section{Figure 1}

Real GDP per head and unemployment, 1986-95

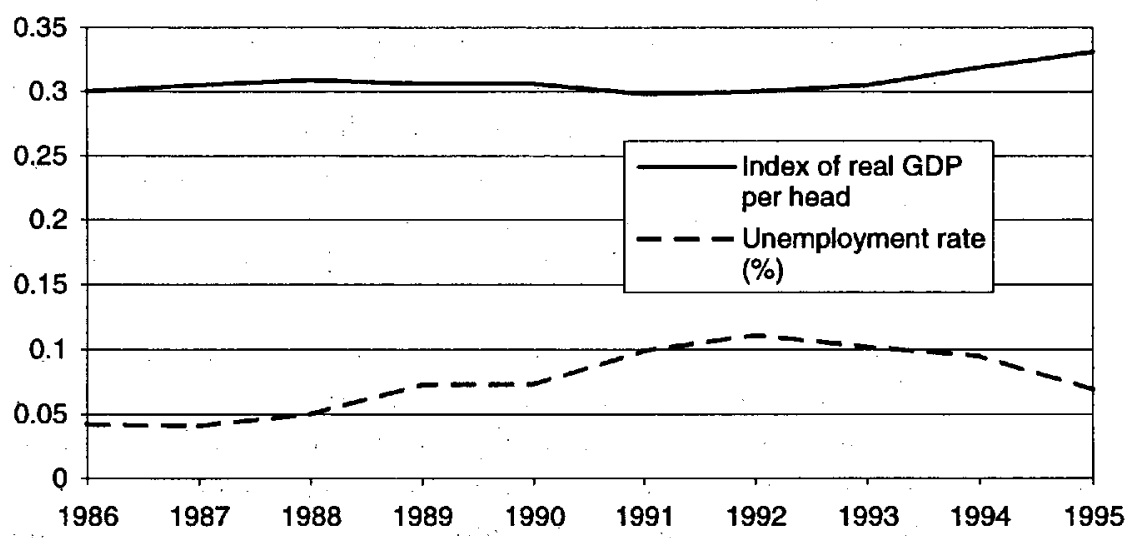

Note: March years.

Source: Statistics New Zealand. 
A second influence on telephone subscribership was the change in social welfare benefit rates and structures of 1991. The rates of unemployment, sickness and domestic purposes (solo-parent) benefits were each reduced by 9 per cent. In addition, 16- and 17-year-olds lost their entitlement to the unemployment benefit, while benefits for 20-24-year-olds were reduced (by 25 per cent) to the youth level. Further, persons receiving income-tested benefits of a long-term nature (excluding the unemployment benefit) lost their entitlement to a telephone benefit that met half the rental. The new benefit regime of 1991 admitted the possibility of persons with a disability having their telephone rental paid by means of a special benefit. By March 1995, the number receiving this benefit was 74 per cent of the number receiving telephone benefits in 1990; but because full rental is paid, aggregate real benefit expenditure was approximately 30 per cent higher. Telecom New Zealand, which was the sole supplier of fixed-wire local residential service over the study period, introduced two tariffs that departed from the standard access tariff. Of these, only the scheme for those over 60 years of age, whereby a much reduced rental is offered in conjunction with a usage charge for local service, has been taken up in significant numbers.

The general benefit rate cuts and the removal of targeted telephone subsidies in 1991 are both likely to have adversely affected telephone subscribership in subsequent years. But separating these two effects from that of the economic downturn is difficult. Because fewer households received a telephone rental subsidy from all sources in 1995 than in 1990, it is presumed that no increase in subscribership between these years can be attributed to changes to welfare benefit policies or the provision of special schemes by Telecom.

\section{Price Rebalancing}

Telecom (1995) reports that the price of the 1995 bundle of calls and access for each of residences and businesses fell in real terms by approximately 50 per cent during 1986-95 (see Figure 2). In addition, prices were rebalanced rapidly over this period. The nominal monthly rental price of a residential line increased from $\mathrm{NZ} \$ 15.06$ to $\$ 27.22$. The fall in the real price of the basket of residential calls that took place after 1986 has been caused entirely by the steep fall in domestic and international toll rates, which offset the heavy increase in the price of residential access.

A long residential access-price series is likely to provide significant information because a household's purchase of access is unlikely to respond very rapidly to price changes. The purchase of access typically entails commitment to communication networks that can be broken only at some cost, even for households. Thus, households' expectations about this commitment as well as future prices and income will influence their decision to purchase or withdraw from telephone access. 
Figure 2

\section{Index of real prices (CPI) of the 1995 basket of residential calls; 1984-95}

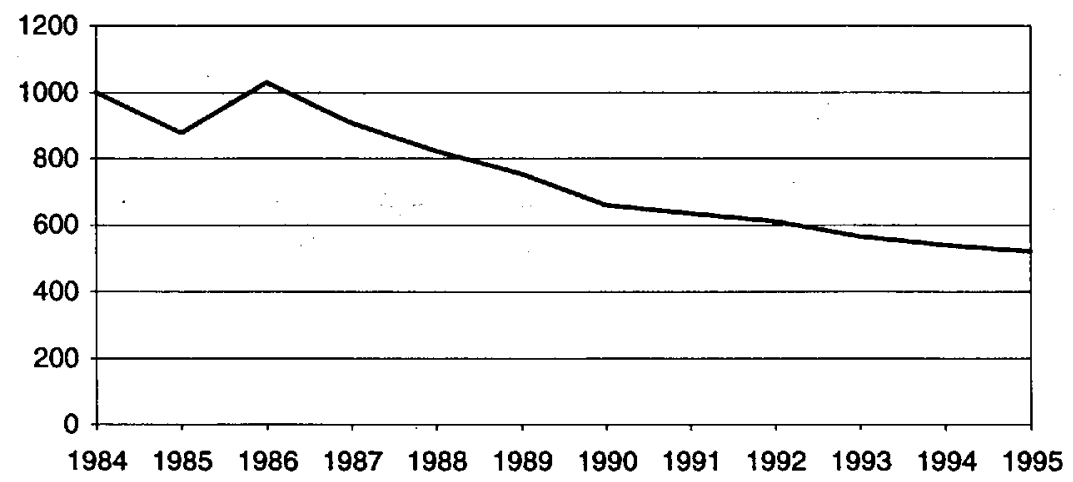

Source: Telecom (1995).

The data displayed in Figure 3 have three key features. First, the real price of access was approximately the same in 1995 as in 1970 . Second, it was relatively low for a long period during the $1980 \mathrm{~s}$, and has been high during the $1990 \mathrm{~s}$ in comparison with the 1980 s. Third, the real price variation caused by infrequently changed, regulated prices during the inflationary periods of the 1970s and mid-1980s is in marked contrast to the stable real prices of the 1990s. Although the inflation rate has been very low in New Zealand during the latter period, access charges have been changed quite frequently to preserve their level in real terms. The Kiwi Share limits the residential access price increases to the rate of price inflation as measured by the CPI, and hence limits the real price of access to its level at the date of privatisation.

The effect of tariff rebalancing in the late 1980 s can be examined by comparing average prices in the relatively stable periods of 1981-88 and 1991-95. In nominal terms, the average monthly price of residential access almost doubled between these periods, rising from NZ\$15.14 to $\$ 29.95$. The horizontal lines in Figure 3 indicate that, between 1981-88 and 1991-95, the average real access price rose by 29 per cent. Because of the relatively long period of lower prices prior to the $1989-90$ adjustments, and the stability of the current well-understood regime, each of these increases is significant and marks a structural change in the residential telephone tariff regime. The 1991-95 period is long enough to permit household responses to the higher real price of access. 


\section{Figure 3}

\section{Residential single line price in constant 1985 (PPO) dollars, 1970-95}

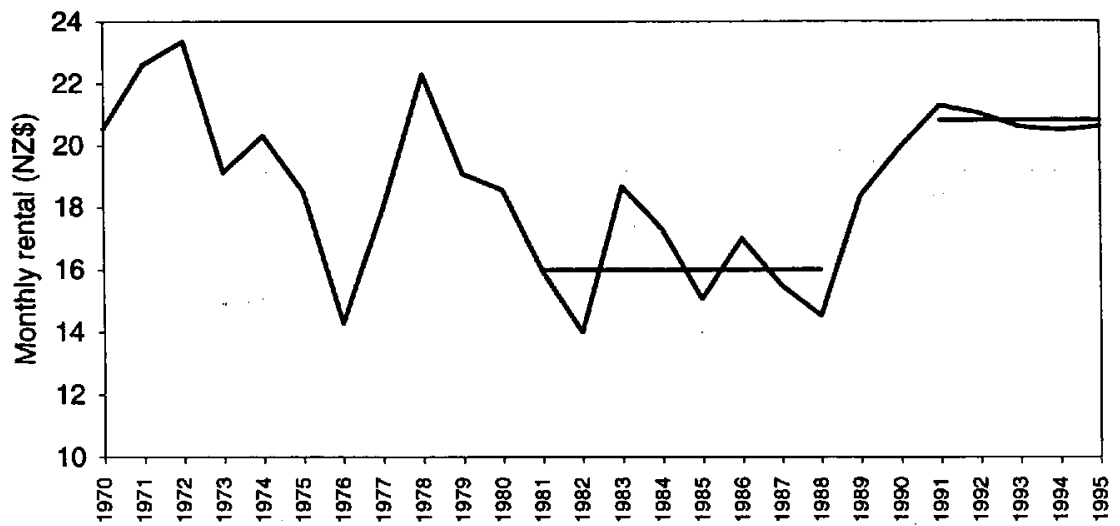

Notes: The horizontal lines depict averages for the 1981-88 and 1991-95 periods. PPO: Statistics New Zealand's Producers' Output Price index. This has been used for deflation in preference to the $\mathrm{CPI}$, because its treatment of interest rates and asset prices indicates how the price of residential access has varied in relation to the prices of goods. As well, it is not directly affected by the introduction of a value-added tax in 1986 and its rate revision in 1988.

Sources: Statistics New Zealand, Telecom New Zealand Ltd., Goodin (1986).

\section{Residential Telephone Subscribership}

Figure 4 depicts the percentage of New Zealand households that have at least one telephone. It shows that there has been very little variation in the penetration rate over the last ten years. Starting at 94.2 per cent in 1985, it rises to 95.7 in 1989 and returns to this level in 1995. Its low point is 93.5 per cent in 1992. These data suggest that New Zealand's telephone penetration rate is virtually the same as, or a percentage point higher in the 1980s, than that reported for the US by Mueller and Schement (1995:3) on the basis of census data.

The confidence band provides a range that takes account of the sampling variability of the estimates of the penetration rate. It suggests that the penetration rate is estimated quite precisely and provides no evidence of a significant difference between the penetration rate of 1995 and the rate prior to the real residential singleline rental price increase of the late 1980s. Despite the expanding presence of cellular telephone alternatives, the fixed-line telephone penetration rate increased after the low point of 1992, and the rate was higher in 1995 than in 1985. 


\section{Figure 4}

\section{Residential telephone access: penetration rate and 95\% confidence interval, 1985-95}

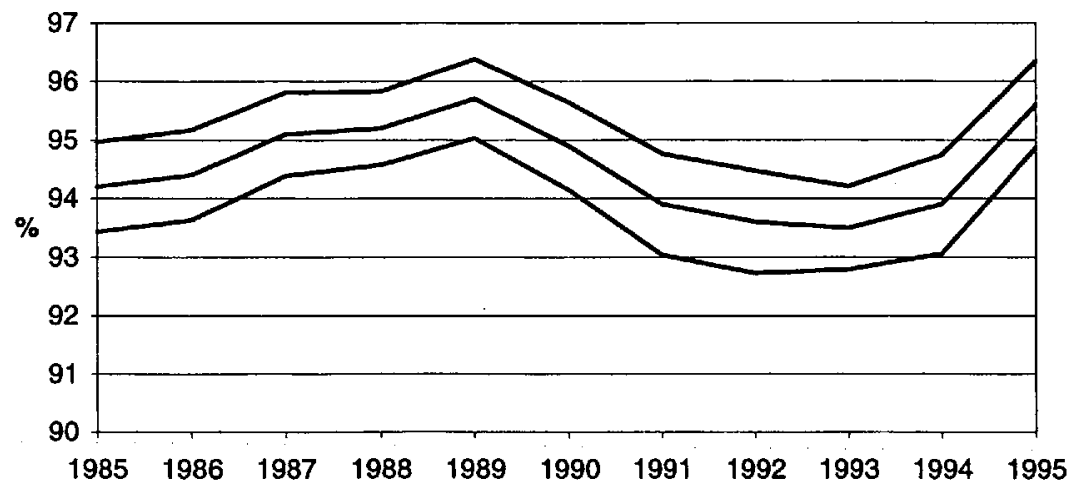

Note: March years.

Source: Statistics New Zealand's Household Survey.

\section{Low-Income Households}

Universal service has typically been concerned with the telephone ownership of lower-income households. Figure 5 depicts the penetration rates by income quartile. The sampling error for the penetration rate of quartile data is necessarily much larger than it is for the aggregate sample. It suggests that there is no difference between the penetration rates of the (poorer) quartiles 1 and 2 and, with the exception of 1992, between 1985 and any other year for the penetration rate of quartile 1 (Evans, 1996).

Figure 5 illustrates the standard finding that the penetration rate is higher for households in high-income groups. The penetration rates of the lower two quartiles are very similar. Households of the second quartile have had very stable penetration rates. The estimated penetration rates of households in the upper three income quartiles have increased over the decade 1985-95.

The downward trend of the penetration rate of quartile 1 (unlike that of the other quartiles) during 1986-89 may reflect the economic restructuring of the reform period. The fact that the penetration rates of quartiles 1 and 2 rose and fell together during most of the 1989-1991 recession suggests that their separation in 1992 reflects the 1991 benefit cuts. At the same time, those in quartile 1 would have been the more severely affected by the recession. Nevertheless, if all persons receiving an access rental benefit belonged to quartile 1, they would represent approximately 24 per cent of households in this quartile, and hence it is likely that the benefit cuts would have some discernible effect. 


\section{Figure 5}

\section{Residential telephone access by income quartile: penetration rates, 1985-95}

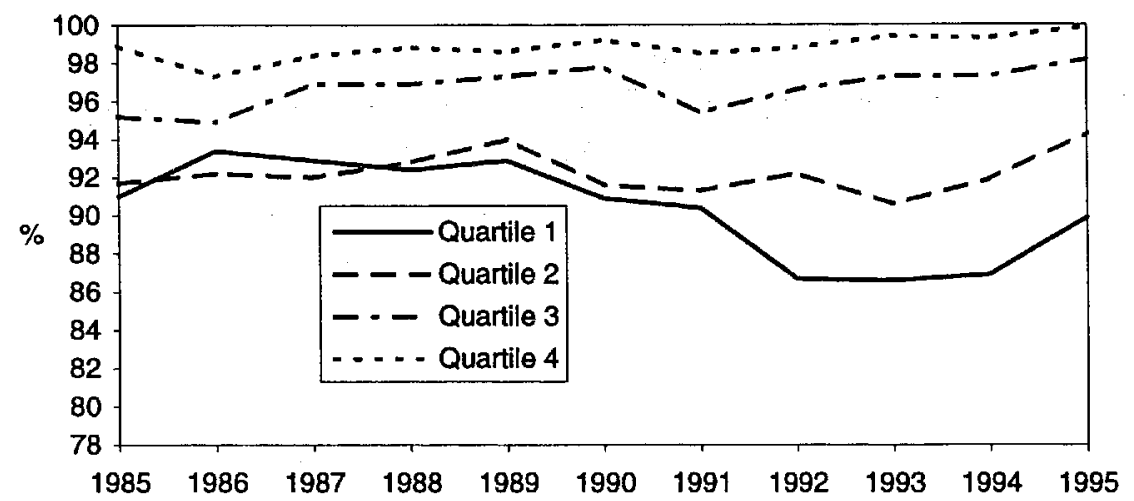

Note: March years.

Source: Statistics New Zealand's Household Survey.

The real price of residential access has remained unchanged during the 1990s. In 1995, the quartile 1 penetration rate of 89.9 per cent is close to its 1985 level of 91 per cent. The fact that as many households were on telephony benefits in 1990 as in 1995, and the rise in the sample penetration rate in the face of a constant real price of access, are indicative that the pattern of telephone penetration for quartile 1 should be attributed to the effects of the business cycle and the benefit cuts. It suggests that Telecom's price rebalancing did not precipitate a reduction in subscribership even among households in the lowest income quartile.

The foregoing analysis suggests that households based their access decision on the price of a bundle of telephony services rather than the price of access only. It requires that households make long-distance calls. In fact, Statistics New Zealand's Household Survey estimates that households in the lowest-income quintile in 1995 spent 28 per cent (up from 21 per cent in 1987) of their telephony expenditure on long-distance services.

Universal service is just part of a full welfare calculation. The decline in the real price of the 1995 bundle of residential calls, together with quality improvements (see Boles de Boer \& Evans, 1996) and an increased range of services implies that household welfare has increased since 1986. While the bundle of services for this real price index will differ from that of households in the bottom income quartile, such is these households' consumption of long-distance calls and the change in the price index that it is likely that the real price of their bundle has also declined. Certainly it has declined since 1990, yielding improvements in these households' welfare between 1990 and 1995. 


\section{References}

Boles de Boer, D. \& L. Evans (1996), 'The Economic Efficiency of Telecommunications in a Deregulated Market: The Case of New Zealand', Economic Record 72 (216): 24-35.

Evans, L. (1996), "The Effect of Telephone Rate Re-Balancing on Residential Access in a De-regulated Economy: Universal Service in New Zealand', mimeo, April.

Goodin, S. (1986), The Demand for Telephone Connections in New Zealand: Analysis and Forecasts, Masters thesis, University of Waikato, Hamilton.

Hausman, J., T. Tardiff \& A. Belinfante (1993), 'The Effects of the Breakup of AT\&T on Telephone Penetration In the United States', American Economic Review 83(2): 178-84.

Mueller, M. \& J. Schement (1995), Universal Service from the Bottom Up, Rutgers University School of Cornmunication, Information and Library Studies, New Brunswick, New Jersey (Rutgers University Project on Information Policy).

Telecom Corporation of New Zealand Ltd (1995), Regulation of Access to Vertically-Integrated Natural Monopolies: Telecom Response, Wellington. 